\title{
Microwave-Assisted Extraction and Ultrasound-Assisted Extraction of Bioactive Compounds from Grape Pomace
}

\author{
${ }^{1}$ Instituto de Ciência e Tecnologia de Alimentos, Federal University of Rio Grande do Sul, Avenida Bento Gonçalves, 9500 , \\ Prédio 43212, Campus do Vale, CEP 91501-970, Porto Alegre 90040-060, RS, Brazil, E-mail: cassiano.cbr@gmail.com, \\ czapatan@ufrgs.br.https://orcid.org/0000-0002-1618-6802.
}

\begin{abstract}
:
The grape pomace is a by-product from the industrial processing of grape juice, which can be used as a source of bioactive compounds. The aim of this study was to separate the phenolic compounds from grape pomace using an acidic aqueous solution with $2 \%$ citric acid as a solvent, using both ultrasound-assisted extraction, with powers of 250, 350 and $450 \mathrm{~W}$ and times of 5, 10 and $15 \mathrm{~min}$, and microwave-assisted extraction using powers of 600, 800 and 1,000 W and times of 5, 7 and $10 \mathrm{~min}$. The results showed that for both methods of extraction, the contents of total phenolic compounds and antioxidant activity by ABTS and DPPH increased with time, and microwave at 1,000 W for $10 \mathrm{~min}$ corresponded to the best extraction condition. However, the contents of phenolic compounds and antioxidant activity were lower than exhaustive extraction using acidified methanol solution.
\end{abstract}

Keywords: pomace, grape, anthocyanins, ultrasound, microwave

DOI: $10.1515 /$ ijfe-2019-0191

Received: June 18, 2019; Revised: November 26, 2019; Accepted: December 29, 2019

\section{Introduction}

Grapes (Vitis vinifera L.) are nonclimacteric fruits, and depending on the species, they may present an intense reddish-purple color due to the large concentration of anthocyanins [1]. The southern region of Brazil stands out for its high productivity and commercialization of grapes and derivatives, with the state of Rio Grande do Sul being responsible for about $90 \%$ of the national wine production and also, according to data from the Brazilian Wine Institute [2], in 2017, about 753,000 tons of grapes were harvested during the season.

Grape processing generates large quantities of residues, mainly during the production of grape juice, as well as during the production of wine, and about $20 \%$ of the weight of processed grapes are considered residues composed mostly of pomace, seeds and stalks [3-5]. In the production of grape juice, the liquid part of the must is extracted for juice production, while the solid pressed part, the pomace, is discarded and used as fertilizer or simply improperly disposed in the environment. However, the pomace can also be used as a source of bioactive compounds with high value-added potential [6-8].

Among the phenolic compounds, anthocyanins are important water-soluble pigments with antioxidant capacity, originated from the secondary metabolism of plants and present in their vascular system and cellular organelles $[4,9]$. Despite being molecules with capacity of incorporation in aqueous systems due to their cationic characteristics, when extracted they can be easily affected by different factors, such as exposure to light and oxygen, high storage temperatures, metallic ions, among others [4, 10]. In parallel with their color attributes, anthocyanin molecules have been associated with several health benefits, mainly due to their antioxidant capacity associated with electron sharing, which may help to prevent diseases related to oxidative stress; they are also used as an alternative to synthetic food colorings [10-12].

The great interest in the antioxidant characteristics of anthocyanins has generated a growing demand, and its commercialization in its purified form or as an extract requires more reproducibility from the separation methods applied in order to increase its large-scale use in food industries. Thus, there is a search for more efficient and sustainable extraction methods for bioactive compounds, so that production costs can be minimized, while taking full advantage of industrial waste in order to transform waste treatment expenses in products with higher added value [12-14]. Conventional extraction methods using organic solvents may expose anthocyanins 
and other phenolic compounds to long periods at high temperatures, often using immersions under agitation involving thermal refluxes that result in degradation through oxidation and thermolysis. In order to decrease the use of these solvents, reduce environmental impact and energy costs with shortest times of exposure to high temperatures and increase extraction efficiency, it is advisable to use unconventional technologies such as microwave-assisted extraction (MAE) and ultrasound-assisted extraction (UAE) for the separation of phenolic compounds [11, 14-16].

Microwaves are electromagnetic waves that penetrate in the food matrix causing polarization of the water molecules followed by an intense dipole-dipole rotational movement, which augments friction between the molecules, increasing kinetic energy and consequently heating the food [11,17]. In the UAE, the sound waves propagate through the food leading to cavitation, and pressure cycles form bubbles oscillating with a non-linear frequency, which collapse when reaching peaks of compression and expansion, producing sonoporation in the disruption of the cell matrix $[11,18]$. The resulting rise in the permeability of the cell membranes contributes to the mass diffusivity increase, improving penetration of the extractive solvent with sonocapilar effect, meaning that small currents are formed where there is solvent fluidity $[11,15,19]$.

The possibility of using processing technologies combining the decrease in organic solvents use with shorter exposure periods for raw materials allows different studies with MAE and UAE to obtain satisfactory yields of polyphenols and anthocyanins. In addition, successive microwave and ultrasound extractions or both combined can be alternatives to reduce energy cost by lowering exposure times and increasing extraction yield [12, 14, 17, 20-23].

The present work aims to study the acidified aqueous extraction of bioactive compounds from grape juice residue through MAE and UAE methods in order to preserve thermolabile compounds and minimize environmental impact, not using organic solvents.

\section{Material and methods}

\subsection{Raw material}

The grape juice pomace (GJP) was donated by Fante Beverage Industry from Rio Grande do Sul, Brazil. Samples were collected from a batch of grape pomace containing a mixture of cultivars in the proportion of $70 \%$ Isabel, $15 \%$ Bordô, $10 \%$ Carmem and 5\% Niagara. Thirty-two kilograms of GJP samples were collected in two batches, cooled and transported in thermal boxes to the Institute of Food Science and Technology of the Federal University of Rio Grande do Sul (ICTA/UFRGS), where they were mixed (homogenizer, Fabbe), packed in polyethylene plastic bags, frozen and stored at $-18^{\circ} \mathrm{C}$ for later use.

\subsection{Characterization of the pomace}

In order to characterize GJP, moisture content (method 984.25) [24], lipids (method 920.39) [24], proteins (method 960.52) [24], fibers (method 991.43) [24], ashes (method 923.03) [24] and carbohydrates (method 984.25) [24] were determined. Water activity (method 978.18) [24] was determined by direct measurement (3TEDecagon Aqualab,) and hydrogen potential was measured by a pH meter (Quimis, Q400M1) (method 973.41) [24]. The moisture content value previously obtained was used to convert all values of concentration from wet basis to dry basis.

\subsection{Extraction}

The GJP was pre-thawed until cooled $\left(4^{\circ} \mathrm{C}\right)$, mixed with distilled water solution acidified with $2 \%(\mathrm{~m} / \mathrm{v})$ citric acid in a ratio of $1: 3(\mathrm{~m} / \mathrm{m})$ using a mechanical stirrer (Ika, RW20) at a speed of $200 \mathrm{rpm}$ for $10 \mathrm{~min}$ and then cooled to $0{ }^{\circ} \mathrm{C}$ for immediate UAE and MAE. For comparison, a third aqueous extraction method (AEX) was performed using the same citric acid solution ratio. For each experiment, a volume of $285 \mathrm{~mL}$ corresponding to $280 \mathrm{~g}$ of extract was used. The factorial $3^{2}$ with three replicates was used to evaluate power and time factors in both ultrasound and microwave methods.

A probe sonicator (Echo-Sonics, QR750) was used for the UAE, and the effect of wave amplitude for powers of 250, 350 and $450 \mathrm{~W}$ and times of 5, 10 and $15 \mathrm{~min}$ was evaluated. A microwave oven (Eletrolux, MEF41) was used in the MAE. The power effect was studied with three levels of 600, 800 and 1,000 W and times of 5, 7 and $10 \mathrm{~min}$. The initial and final temperatures after each treatment were measured at the geometric center point of 
the samples using a type-K thermocouple (Full Gauge, Penta). For comparison, the AEX consisted in allowing the extract to stand for $24 \mathrm{~h}$ in a dark chamber at room temperature [25].

After the extractions, samples were immediately cooled to room temperature $\left(20^{\circ} \mathrm{C}\right)$, centrifuged at $3,000 \times g$ speed for $10 \mathrm{~min}$, vacuum filtered with Whatman $\mathrm{n}^{\circ} 1$ paper, then the filtrate was stored at $-20^{\circ} \mathrm{C}$ and the retentate was discarded. The response variables for the extracts were total phenolic compounds, total monomeric anthocyanins (TMAs), antioxidant activity by ABTS and DPPH and color. All procedures were performed protected from light.

An exhaustive extraction of GJP was performed according to the methodology described by Sánchez-Alonso et al. [26] with some modifications [27]. One gram of GJP was mixed with $10 \mathrm{~g}$ of solution of $80 \%(\mathrm{v} / \mathrm{v})$ methanol acidified with $1 \% \mathrm{HCl}$ and vortexed (Quimis, Q920- A2) for $10 \mathrm{~min}$. The solution was then centrifuged (Sigma, $4 \mathrm{~K} 15) 3,000 \times \mathrm{g}$ for $10 \mathrm{~min}$. The supernatant was filtered with Whatman $\mathrm{n}^{\circ} 1$ filter paper and reserved in a $50 \mathrm{~mL}$ volumetric flask, and the retentate was subjected to four more extractions. The supernatants had the final volume adjusted with the same methanolic solution and the final retention was discarded.

\subsection{Total phenolic compounds}

The TPC content was determined using the Folin-Ciocalteau colorimetric method with modifications [28] at the wavelength of $765 \mathrm{~nm}$. The readings were done on UV-visible spectrophotometer (Thermo Scientific, Genesys S10), and the results are expressed in milligrams of gallic acid equivalent (GAE) per gram of d.b.

\subsection{Total monomeric anthocyanins}

For the analysis of TMA, aliquots of the extracts were added in buffer solutions of potassium chloride and sodium acetate according to the methodology by Lee et al. [29]. The readings were carried out in UV-visible spectrophotometer at $520 \mathrm{~nm}$ and at $700 \mathrm{~nm}$, and the results were calculated according to eq. (1) and expressed in milligrams of malvidin-3,5-diglycoside per gram of d.b.

$$
T M A=\frac{\left[\left(A b s_{520 n m}-A b s_{700 n m}\right)_{p H 1,0}-\left(A b s_{520 n m}-A b s_{700 n m}\right)_{p H 4,5}\right] \times M \times D F \times 100}{\varepsilon \times l}
$$

where

$M=$ molar mass of malvidine-3,5-diglycoside equivalent $\left(724.5 \mathrm{~g} \cdot \mathrm{mol}^{-1}\right)$;

$D F=$ dilution factor;

$\varepsilon=$ extinction molar coefficient $\left(37,000 \mathrm{~L} \cdot \mathrm{mol}^{-1} \cdot \mathrm{cm}^{-1}\right)$;

$l=$ optical path of the cuvette $(1 \mathrm{~cm})$.

\subsection{Antioxidant activity}

The antioxidant activity was evaluated by two spectrophotometric methods. The ABTS radical (2,2'-azino-bis (3ethylbenzothiazoline-6-sulfonic acid)) scavenging activity was measured by the method of Re et al. [30]. The second method, the radical DPPH (2,2-diphenyl-1-picrylhydrazyl), was carried out according to Brand-Williams et al. [31]. For both methods, the absorbance was measured in an UV-visible spectrophotometer, using wavelength at 734 and $515 \mathrm{~nm}$ for ABTS and DPPH, respectively. The results are expressed as micromol ( $\mu \mathrm{mol})$ of Trolox (6-hydroxy-2,5,7,8-tetramethylchroman-2-carboxylic acid) equivalent (TE) per gram of d.b.

\subsection{Colorimetric analysis}

The color measurement was performed by a colorimeter (Minolta, CR400/410), with the CIEL $L^{*} b^{*}$ threedimensional system. The parameters of Chroma (color saturation) and Hue angle (color tone) were calculated from the measurements of the coordinates referring to luminosity $\left(L^{*}\right.$, where the indicative scale ranges from 0 to 100 , from black to white), and where $a^{*}$ and $b^{*}$ indicate an axis with values between -60 and +60 , ranging from green to red and from blue to yellow, respectively, according to eqs. (2), (3) and (4) [32, 33]:

$$
\text { Chroma }=\left(a^{* 2}+b^{* 2}\right)^{\frac{1}{2}}
$$




$$
H u e=\operatorname{tg}^{-1}\left(\frac{b^{*}}{a^{*}}\right)
$$

\subsection{Statistical analysis}

For the analysis of the main effects and interaction, the results were submitted to analysis of variance (ANOVA). The Tukey test was used for multiple comparison of means, with a significance of $5 \%$. Pearson's correlation was used to establish relationships between TPC, TMA, ABTS, DPPH, $L^{*}, a^{*}$ and $b^{*}$. The calculations were performed using the statistical software SAS (Statistical Analysis System, version 9.3).

\section{Results and discussion}

\subsection{Pomace}

Table 1 shows the centesimal composition of GJP. The low moisture value of $3.81 \mathrm{~g} \bullet 100 \mathrm{~g}^{-1} \mathrm{might}$ be due to the separation of the liquid part (juice) from pomace, leading to a higher concentration of solid matter. The low moisture value may be due to the high efficiency in the process of juice extraction used by the industry. Similar

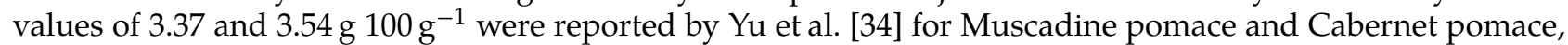
respectively. The same is observed for the carbohydrate content of GJP, since carbohydrate oligomers are reducing sugars, with high solubility; they are easily extracted mainly due to their presence in the cytosol in the free form, and in cellular organelles, such as vacuoles, they are easily leaked by cell disruption during maceration of grapes [11]. This material is also characterized by a high content of lipids and fibers, mainly due to the presence of stalks, barks and seeds that were macerated for the juice extraction and pomace formation. Concerning the protein content, in addition to what has already been mentioned, it is also necessary to emphasize the presence of pectinolytic enzymes that were purposely added during the berries crushing.

Table 1: Centesimal composition of grape juice pomace (GJP).

\begin{tabular}{|c|c|}
\hline & GJP \\
\hline Moisture & $3.81 \pm 0.2$ \\
\hline$a_{\mathrm{w}}$ & $0.978 \pm 0.003$ \\
\hline $\mathrm{pH}$ & $3.41 \pm 0.02$ \\
\hline Protein & $31.1 \pm 0.0$ \\
\hline Lipid & $5.4 \pm 0.1$ \\
\hline Fiber & $12.9 \pm 0.4$ \\
\hline Carbohydrate & $47.6 \pm 0.0$ \\
\hline Ash & $3.0 \pm 0.0$ \\
\hline
\end{tabular}

Values are constituent gram per 100 grams of GJP $\left(\mathrm{g} \bullet 100 \mathrm{~g}^{-1}\right)$ on dry basis except for water activity $\left(\mathrm{a}_{\mathrm{w}}\right)$ and $\mathrm{pH}$ which are dimensionless.

These enzymes are added in the must with the purpose of breaking the cell walls, improving the release of sugars and phenolic compounds from grape skin, intensifying color as well as decreasing must viscosity [35].

\subsection{Extraction process}

The concentrations of TPC obtained in the different extraction treatments can be visualized in Figure 1. ANOVA indicates that the main factors of power and time of exposure, as well as the power-time interaction, were statistically significant for both UAE and MAE. Figure 1 shows that the TPC levels in the MAE for power of 1,000 W with the times of 5, 7 and 10 min were significantly higher than that obtained in the other treatments, presenting $10 \mathrm{~min}$ as the greater separation time $(p<0.05)$. Regarding the UAE treatments, the highest separation yield obtained was at $450 \mathrm{~W}$ and $15 \mathrm{~min}$. All other separation conditions, including the AEX for $24 \mathrm{~h}$, presented unsatisfactory yields. 


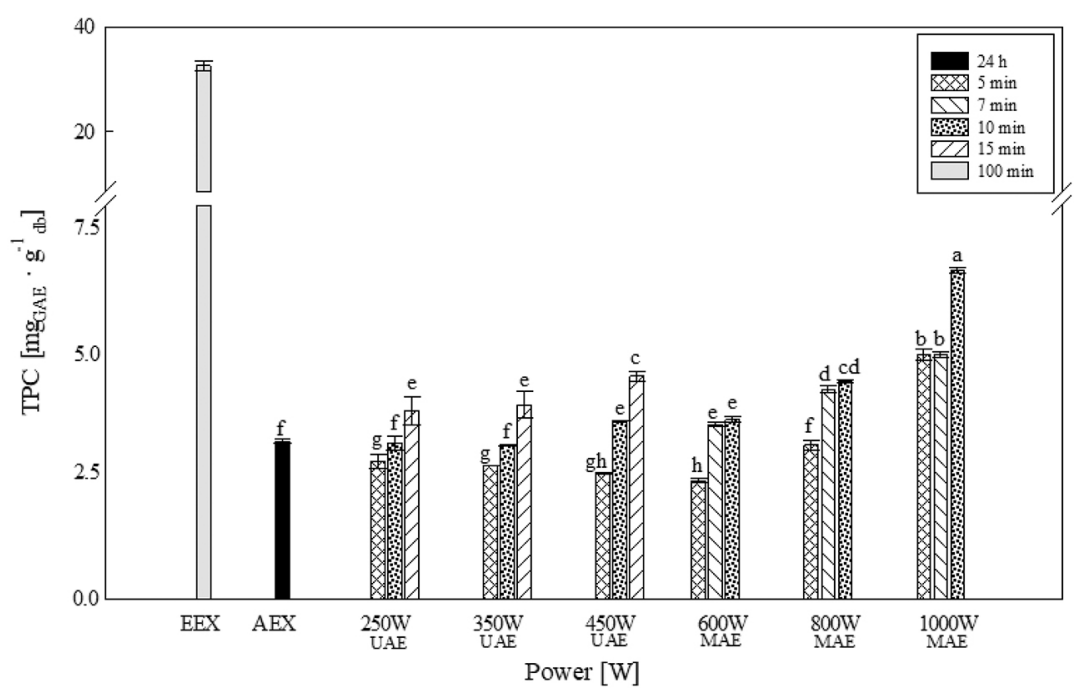

Figure 1: Total phenolic compounds (TPC) of the treatments with ultrasound-assisted extraction (UAE), microwaveassisted extraction (MAE), exhaustive extraction (EEX) and aqueous extraction (AEX). Different letters indicate significant differences $(p<0.05)$.

Liazid et al. [20], in a study using MAE for the phenolic compounds extraction of grape hulls, observed that under optimum separation conditions of $500 \mathrm{~W}$, at $100{ }^{\circ} \mathrm{C}$ in $40 \%(\mathrm{v} / \mathrm{v})$ methanol, the time applied of $5 \mathrm{~min}$ was much lower than the $5 \mathrm{~h}$ employed in conventional extraction with methanol: formic acid (95:5) protected from light and under refrigeration $\left(7^{\circ} \mathrm{C}\right)$. The action of the microwave electromagnetic waves in the GJP food matrix presents greater effectiveness in the energy transformation; thus, a lower extraction time of the solvent is sufficient along with the elevation of the temperatures to increase the kinetic diffusion coefficients and reduce the resistance to mass transfer, consequently allowing a larger diffusion of the solvent through the food [20].

For each power, in both ultrasound and microwave methods, it was observed that the extraction yield of phenolic compounds increased with the exposure time. Goula et al. [36], in a study with UAE of grape pomace phenolic compounds using a sonicator with a power of $130 \mathrm{~W}$, times of 4 to $60 \mathrm{~min}$, different concentrations of ethanol and methanol and different ratios between solvent-bagasse, observed that the yields of phenolic compounds in the extractions increased with time, and the time of $10 \mathrm{~min}$ demonstrated to be the most efficient.

The same study verified that the ultrasound waves act in the first moments of extraction, where the cavitational effects in the solvent near the vegetal materials form microchannels toward the food matrix, resulting in a greater penetration of the solvent. However, over time, there is a greater action of the waves in the rupture of the cellular structures causing leakage of the extracted constituents which may affect the capacity of mass transfer, thus diminishing the permeability of the solvent in the cellular structures.

Zeković et al. [16] reported the separation of phenolic compounds in Salvia officinalis L., with ethanol $60 \%$ as solvent; the optimum extraction conditions were as follows: time of $80 \mathrm{~min}$, power of $42.54 \mathrm{~W} \bullet \mathrm{L}^{-1}$ and temperature of 75.4 C for UAE and time of $18.7 \mathrm{~min}$ and power of $600 \mathrm{~W}$ for MAE. In the same study, significantly higher yields of TPC and total flavonoids were observed for both UAE and MAE when compared to a conventional solid-liquid extraction with organic solvents for $24 \mathrm{~h}$ under agitation.

The elevations of the temperatures observed in the separations by MAE and UAE are in direct relation with the increase of power and time employed, and in both cases, the elevation of the temperature tends to increase the solvent diffusion coefficients through the cellular matrix, increasing the yield [17]. This increase in temperature, in the case of UAE, may be due to the cavitation effect in the liquid-solid system caused by the collapse of the bubbles formed; and in the case of the MAE, it may be due to the energy released by the dipole rotation of the water and the friction between them $[11,18]$. In our experiments, the temperature gradients (difference of final and initial temperatures) in the various treatments were in the range of $35.6 \pm 3.0$ to $88.1 \pm 1.8^{\circ} \mathrm{C}$ in the UAE, being greater for higher powers and times. In the case of MAE, the temperature gradients were from $35.0 \pm 1.8$ to $93.5 \pm 4.9^{\circ} \mathrm{C}$. Thus, the use of UAE and MAE may be able to accelerate the solubilization of analytes caused by the increase in temperature, resulting in lower extraction times when compared to exhaustive extraction $[17,37,38]$. The temperatures for each method are shown in Table 2.

Table 2: Final temperatures reached after extraction.

\begin{tabular}{ll} 
Treatments & Temperature $\left({ }^{\circ} \mathbf{C}\right)$ \\
\hline UAE $(250 \mathrm{~W}-5 \mathrm{~min})$ & $35.6 \pm 3.0$ \\
UAE $(250 \mathrm{~W}-10 \mathrm{~min})$ & $62.7 \pm 6.2$
\end{tabular}


UAE (250 W-15 min)

UAE ( $350 \mathrm{~W}-5 \mathrm{~min}$ )

UAE (350 W-10 min)

UAE (350 W-15 min)

UAE (450 W-5 min)

UAE (450 W-10 min)

UAE (450 W-15 min)

MAE (600 W-5 min)

MAE (600 W-7 min)

MAE (600 W-10 min)

MAE (800 W-5 min)

MAE (800 W-7 min)

MAE (800 W-10 min)

MAE (1,000 W-5 min)

$\operatorname{MAE}(1,000 \mathrm{~W}-7 \mathrm{~min})$

$\operatorname{MAE}(1,000 \mathrm{~W}-10 \mathrm{~min})$
$81.3 \pm 0.2$

$42.5 \pm 2.0$

$63.9 \pm 1.4$

$84.3 \pm 1.1$

$49.8 \pm 5.0$

$75.6 \pm 0.3$

$88.1 \pm 1.8$

$35.0 \pm 1.8$

$53.0 \pm 2.8$

$71.5 \pm 4.1$

$44.4 \pm 4.4$

$66.7 \pm 0.7$

$83.1 \pm 3.3$

$57.7 \pm 5.7$

$84.8 \pm 4.7$

$93.5 \pm 4.9$

UAE refers to ultrasound-assisted extraction; MAE refers to microwave-assisted extraction.

In Figure 2, the TMA obtained in the different separation conditions can be observed. The highest extractions yields were obtained by MAE at power of 800 and 1,000 W for $7 \mathrm{~min}(p<0.05)$, and when time was increased to $10 \mathrm{~min}$ the contents decreased significantly. Evaluating ANOVA, it shows that power, time and power-time interaction have a significant impact on the results obtained for TMA in MAE. Benmeziane et al. [39] observed that with increasing exposure time to high temperatures produced, some phenolic compounds which present weak molecular interactions with glycosides, including anthocyanin monomers, significantly decreased their concentrations. Liazid et al. [20] mentioned that phenolic compounds, among them anthocyanins, may be degraded due to the time of exposure, the extraction heating and the energy applied by MAE; in addition, reactions between the compounds themselves, oxy-redox reactions and hydrolysis that may change the nature of the compounds can occur. As well, polymerization reactions may occur, forming phenolic compounds with greater or lesser antioxidant activity [25], although the new compounds formed cannot be quantified by the analytical method, which is specific to anthocyanic monomers present in the samples [29]. Our results for MAE showed a similar behavior for the concentration over time to each power employed; while for the same time, the concentration increased with the power (Figure 2); however, at 10 min of extraction the concentrations decreased. For UAE, at the same time, there were no significant differences among the powers, although TMA contents increased with time.

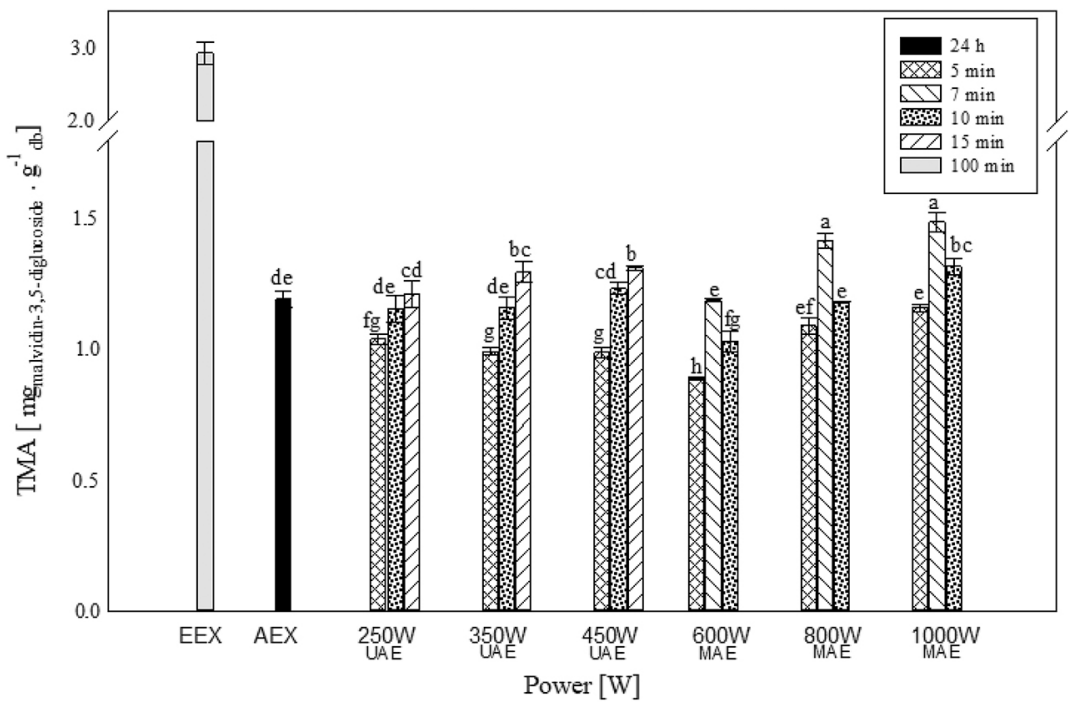

Figure 2: Total monomeric anthocyanins (TMA) of the treatments with ultrasound-assisted extraction (UAE), microwaveassisted extraction (MAE), exhaustive extraction (EEX) and aqueous extraction (AEX). Different letters indicate significant differences $(p<0.05)$.

ANOVA indicated that for UAE, the power was not significant, possibly due to the fact that the ultrasound powers used were not sufficiently effective for the breakdown of the cellular food matrix when evaluated alone. Likewise, the power-time interaction was also not significant, being only significant the time of exposure in the TMA content. Consequently, the best UAE obtained was with the power of 350 and $450 \mathrm{~W}$ in the longest time 
applied of $15 \mathrm{~min}$, demonstrating that higher yields of TMA are obtained with longer times. In both methods, UAE and MAE, the worst yields obtained were for times shorter than $7 \mathrm{~min}$.

As for the antioxidant activity by the ABTS and DPPH, ANOVA indicated that power, time, and interaction factors were statistically significant $(p<0.05)$ for both ultrasound and microwave methods.

In Figure 3A, it was observed that for ABTS, the MAE in the condition of $1,000 \mathrm{~W}$ and $10 \mathrm{~min}$, was significantly higher in comparison with the other treatments. The antioxidant activity of the extracts is directly related to the behavior of the phenolic compound content present in the samples, since the set of antioxidants is formed by different compounds, considering that the antioxidants neutralize free radical species by donating one of their own electrons to afford them stability [40].
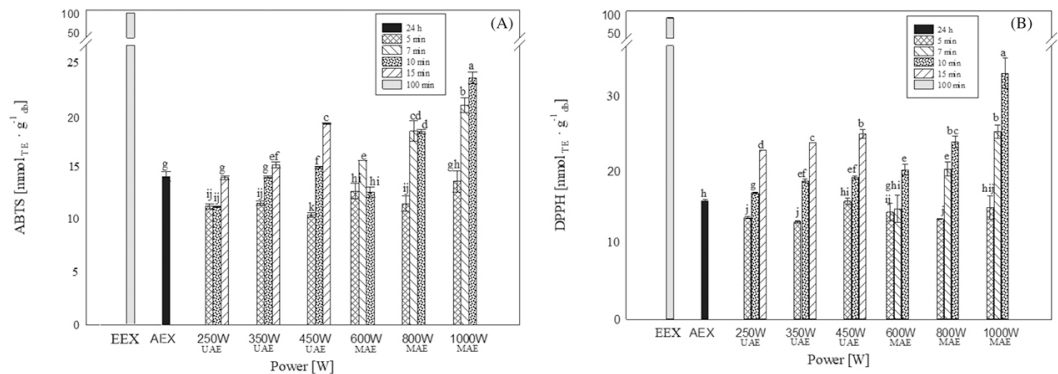

Figure 3: Antioxidant activity by ABTS (A) and by DPPH (B) of the treatments with ultrasound-assisted extraction (UAE), microwave-assisted extraction (MAE), exhaustive extraction (EEX) and aqueous extraction (AEX). Different letters indicate significant differences $(p<0.05)$.

In the antioxidant activity by DPPH (Figure 3B), the treatment of extraction at $1,000 \mathrm{~W} \times 10 \mathrm{~min}$ by MAE was significantly higher in relation to the other treatments. Ultrasound $(450 \mathrm{~W} \times 15 \mathrm{~min})$ and microwave treatments of $800 \mathrm{~W} \times 10 \mathrm{~min}$ and $1,000 \mathrm{~W} \times 7 \mathrm{~min}$ were also significantly different from the others, and when compared with AEX, they obtained yields of at least $40 \%$ higher. The technologies of extraction by ultrasound and microwaves bring an increase in the yield of bioactive compounds with smaller times of extraction in relation to the conventional processes, as the action of sound waves and of microwaves can generate hydroxyl free radicals, peroxyl, among other chain reactions precursors linked to oxidative stress, from the breakdown of polymeric structures of food matrices [19, 38, 41].

Although water has a high dielectric constant, data showed a low recovery of the phenolic compounds; thus, antioxidant activity was low. The extraction of bioactive compounds is largely dependent on other factors such as solubility, acid-base properties and hydrophobicity [42]. For this reason, the grape pomace suspension prepared in acidified aqueous solution presented high polarity becoming unsuitable for extraction and showing low extraction yield.

The color parameters of the extracts obtained are presented in Table 3. It can be observed in the parameter of luminosity ( $L^{*}$, where the scale ranges from 0 to 100, from black to white) for MAE that darker samples were obtained with the lowest times. The contrary is demonstrated for UAE, where the darker samples were obtained with the longer exposure time. For the color parameters $a^{*}$ and $b^{*}$, which indicate an axis with values between -60 and +60 , ranging from green to red and from blue to yellow, respectively; all treatments presented positive values indicating the spectrum of yellow to red. The Pearson correlation values showed a strong relationship between TPC and TMPA with ABTS, DPPH, $a^{*}$ and $L^{*}$; however, for $b^{*}$ parameter, there was a low correlation between TMA, ABTS and DPPH (Table 4).

Table 3: Colorimetric parameters $\left(L^{*}, a^{*}, b^{*}, H u e\right.$, Chroma) of extracts obtained from grape juice pomace (GJP).

\begin{tabular}{|c|c|c|c|c|c|}
\hline Treatments & $L^{*}$ & $a^{*}$ & $b^{*}$ & Hиe $\left(^{\circ}\right)$ & Chroma \\
\hline GJP & $28.9 \pm 1.0$ & $13.9 \pm 0.2$ & $1.5 \pm 0.3$ & $6.1 \pm 1.2$ & $14.0 \pm 0.2$ \\
\hline AEX & $57.4 \pm 0.5^{c}$ & $41.1 \pm 0.4^{\text {ghij }}$ & $6.1 \pm 0.3^{b}$ & $8.6 \pm 0.1^{\mathrm{h}}$ & $38.6 \pm 0.7^{\mathrm{h}}$ \\
\hline UAE (250 W-5 min) & $60.9 \pm 1.0^{\mathrm{ab}}$ & $36.6 \pm 1.6^{\mathrm{kl}}$ & $4.6 \pm 0.4^{\mathrm{h}}$ & $7.2 \pm 0.3^{i}$ & $36.9 \pm 1.6^{\mathrm{i}}$ \\
\hline UAE (250 W-10 min) & $58.6 \pm 1.3^{\mathrm{bc}}$ & $39.4 \pm 1.9^{\text {hijk }}$ & $5.7 \pm 0.7 \mathrm{gh}$ & $8.2 \pm 0.7^{\mathrm{hi}}$ & $39.8 \pm 2.0^{\mathrm{hi}}$ \\
\hline UAE ( $250 \mathrm{~W}-15 \mathrm{~min})$ & $55.8 \pm 1.8^{\text {cde }}$ & $41.3 \pm 1.8^{\text {fghi }}$ & $7.5 \pm 1.2^{\mathrm{fg}}$ & $10.2 \pm 1.1^{\text {efg }}$ & $42.0 \pm 2.0^{\mathrm{fgh}}$ \\
\hline UAE (350 W-5 min) & $61.1 \pm 0.1^{\mathrm{a}}$ & $36.5 \pm 0.1^{1}$ & $4.5 \pm 0.0^{\mathrm{h}}$ & $7.0 \pm 0.0^{i}$ & $36.8 \pm 0.1^{\mathrm{i}}$ \\
\hline UAE (350 W-10 min) & $58.3 \pm 0.6^{c}$ & $39.5 \pm 1.3^{\mathrm{ijk}}$ & $5.9 \pm 0.4^{g}$ & $8.5 \pm 0.3^{h}$ & $39.9 \pm 1.4^{\mathrm{h}}$ \\
\hline UAE (350 W-15 min) & $55.0 \pm 1.6^{\text {de }}$ & $41.8 \pm 1.8^{\text {fghi }}$ & $7.8 \pm 1.1^{\text {ef }}$ & $10.5 \pm 1.0$ efg & $42.5 \pm 2.0^{\text {efgh }}$ \\
\hline UAE (450 W-5 min) & $61.5 \pm 0.5^{\mathrm{a}}$ & $35.7 \pm 0.7^{1}$ & $4.3 \pm 0.3^{h}$ & $6.8 \pm 0.3^{i}$ & $35.9 \pm 0.7^{i}$ \\
\hline UAE (450 W-10 min) & $56.0 \pm 0.1^{\mathrm{d}}$ & $41.5 \pm 0.5^{\mathrm{gh}}$ & $7.3 \pm 0.0^{f}$ & $10.0 \pm 0.1^{\mathrm{g}}$ & $42.2 \pm 0.5^{\mathrm{gh}}$ \\
\hline UAE (450 W-15 min) & $53.2 \pm 0.2^{f}$ & $41.7 \pm 0.3^{g}$ & $9.1 \pm 0.2$ de & $12.3^{2} 0.3^{\mathrm{d}}$ & $42.7 \pm 0.3^{g}$ \\
\hline MAE (600 W-5 min) & $52.1 \pm 0.9^{f}$ & $48.1 \pm 1.3^{b c}$ & $12.5 \pm 1.1^{b c}$ & $14.5 \pm 0.8^{b c}$ & $49.7 \pm 1.5^{b c}$ \\
\hline
\end{tabular}




\begin{tabular}{|c|c|c|c|c|c|}
\hline MAE (600 W-7 min) & $57.0 \pm 0.6^{\text {cdef }}$ & $42.0 \pm 0.3^{\text {cdef }}$ & $7.5 \pm 0.4^{\text {cdef }}$ & $12.3 \pm 1.7^{\text {cdef }}$ & $42.7 \pm 0.4^{\text {cdef }}$ \\
\hline MAE (600 W-10 min) & $60.4 \pm 1.0^{\mathrm{ab}}$ & $39.9 \pm 0.6^{j \mathrm{kl}}$ & $7.6 \pm 1.1^{\mathrm{g}}$ & $8.6 \pm 0.5^{\mathrm{fg}}$ & $40.4 \pm 0.7^{\mathrm{h}}$ \\
\hline MAE (800 W-5 min) & $50.6 \pm 1.4^{\text {gh }}$ & $49.2 \pm 0.6^{b}$ & $13.8 \pm 1.4^{\mathrm{ab}}$ & $15.7 \pm 1.3^{\mathrm{ab}}$ & $51.1 \pm 1.0^{\mathrm{b}}$ \\
\hline MAE (800 W-7 min) & $54.6 \pm 0.2^{\mathrm{e}}$ & $43.4 \pm 0.8^{\text {ef }}$ & $7.7 \pm 0.2^{f}$ & $10.1 \pm 0.0^{\mathrm{g}}$ & $44.0 \pm 0.8^{\text {ef }}$ \\
\hline MAE (800 W-10 min) & $54.9 \pm 0.1^{\mathrm{e}}$ & $44.3 \pm 0.1^{\mathrm{e}}$ & $8.2 \pm 0.2^{f}$ & $10.5 \pm 0.2^{\mathrm{f}}$ & $45.1 \pm 0.1^{\mathrm{de}}$ \\
\hline $\operatorname{MAE}(1,000 \mathrm{~W}-5 \mathrm{~min})$ & $47.5 \pm 1.8^{\mathrm{h}}$ & $50.2 \pm 0.1^{\mathrm{a}}$ & $16.7 \pm 1.7^{\mathrm{a}}$ & $18.3 \pm 1.7^{\mathrm{a}}$ & $53.0 \pm 0.7^{\mathrm{a}}$ \\
\hline MAE (1,000 W-7 min) & $51.8 \pm 0.0^{g}$ & $46.0 \pm 1.1^{\mathrm{cd}}$ & $9.7 \pm 0.4^{\mathrm{d}}$ & $12.0 \pm 0.2^{\mathrm{d}}$ & $47.0 \pm 1.2^{\mathrm{d}}$ \\
\hline $\operatorname{MAE}(1,000 \mathrm{~W}-10 \mathrm{~min})$ & $52.7 \pm 0.8^{\mathrm{fg}}$ & $45.2 \pm 0.8$ de & $9.5 \pm 0.8$ de & $11.9 \pm 0.7 \mathrm{de}$ & $46.2 \pm 0.9^{d}$ \\
\hline
\end{tabular}

GJP refers to grape juice pomace; AEX refers to aqueous extraction at room temperature $\left(20^{\circ} \mathrm{C}\right)$ for $24 \mathrm{~h}$; UAE refers to ultrasound-assisted extraction; MAE refers to microwave-assisted extraction; different letters in the same column indicate significant differences $(p<0.05)$.

Table 4: Pearson correlation coefficients between total phenolic compounds, total monomeric anthocyanins, ABTS, DPPH, $L^{*}, a^{*}$ and $b^{*}$ of extraction from grape pomace.

\begin{tabular}{llllllll}
\hline & TPC & TMA & ABTS & DPPH & $\boldsymbol{L}^{*}$ & $\boldsymbol{a}^{*}$ & $\boldsymbol{b}^{*}$ \\
\hline TPC & $\mathbf{1}$ & 0.9637 & 0.9958 & 0.9802 & -0.8832 & -0.7966 & -0.729 \\
TMA & 0.9637 & $\mathbf{1}$ & 0.9713 & 0.9644 & -0.8668 & -0.7456 & -0.3790 \\
ABTS & 0.9958 & 0.9713 & $\mathbf{1}$ & 0.9841 & -0.8778 & -0.7950 & -0.3932 \\
DPPH & 0.9802 & 0.9644 & 0.9841 & $\mathbf{1}$ & -0.8510 & -0.7796 & -0.4020 \\
$L^{*}$ & -0.8832 & -0.8668 & -0.8778 & -0.8510 & $\mathbf{1}$ & 0.4452 & -0.0759 \\
$a^{*}$ & -0.7966 & -0.7456 & -0.7950 & -0.7796 & 0.4452 & $\mathbf{1}$ & 0.8213 \\
$b^{*}$ & -0.3729 & -0.3790 & -0.3932 & -0.4020 & -0.0759 & 0.8213 & $\mathbf{1}$ \\
\hline
\end{tabular}

${ }^{1}$ (TPC) total phenolic compounds; (TMA) total monomeric anthocyanins; $\left(L^{*}, a^{*}, b^{*}\right)$ colorimetric parameters; antioxidant activity by ABTS and DPPH.Add a table footnote here

The Hue angle indicates that all treatments presented values in the first quadrant and in the first quarter (0 to $22.5^{\circ}$ ), indicating the reddish tone of the extracts. The color saturation is given by the Chroma parameter, and the MAE treatments generally obtained significantly more saturated colors (40.4 to 53.0) than the UAE (35.9 to 42.7) and AEX (38.6) treatments.

The inherent characteristics of the various grape cultivars present in GJP indicate the genetic influence on the profile of the anthocyanins present in the extracts and consequently their coloration. According to Gordillo et al. [43], in their study of the anthocyanin staining stability of different grape cultivars, the high proportions of co-pigments present in the extracts reflect on the effects of anthocyanin color saturation and the hue with angles in the first quarter of the first quadrant, indicating more purely red colors attributed to the different proportions of monoglycosides and acylated anthocyanins. In this study, the GJP used is composed of different proportions of grapes of the cultivars Isabel, Bordô, Carmem and Niagara. Also, regarding the effects of the extract coloration, the recovery of anthocianins indicates that the cellular changes promoted by the application of ultrasound or microwaves encourage the release of these compounds. However, they may influence the ability of these compounds to react, favoring glycosylation, acylation, polymerization and hydrolysis reactions, and this way could change on the antioxidant activity $[25,33,43]$.

The best extraction condition was obtained by MAE with a power of 1,000 W and time of $10 \mathrm{~min}$, with levels of TPC, TMA, antioxidant activity by ABTS and DPPH of $6.68 \pm 0.05 \mathrm{mg}_{\mathrm{GAE}} \bullet \mathrm{g}^{-1}$ (d.b), $1.32 \pm 0.03$ $\mathrm{mg}_{\text {malvidin-3,5-diglycoside }} \mathrm{g}^{-1}$ (d.b), $23.84 \pm 0.57 \mu \mathrm{mol}_{\mathrm{TE}} \bullet \mathrm{g}^{-1}$ (d.b) and $33.27 \pm 2.00 \mu \mathrm{mol}_{\mathrm{TE}} \bullet \mathrm{g}^{-1}$ (d.b), respectively. When compared with the results obtained by exhaustive extraction of GJP, $32.58 \pm 0.93 \mathrm{mg}_{\mathrm{GAE}}^{\bullet g^{-1}}$ (d.b), $2.93 \pm 0.15 \mathrm{mg}_{\text {malvidin-3,5-diglycoside }} \mathrm{g}^{-1}$ (d.b), $100.91 \pm 0.01 \mu \mathrm{mol}_{\mathrm{TE}} \bullet \mathrm{g}^{-1}$ (d.b) and $92.20 \pm 0.57 \mu \mathrm{mol}_{\mathrm{TE}} \mathrm{gg}^{-1}(\mathrm{~d} . \mathrm{b})$ for TPC, TMA, ABTS and DPPH, respectively, those values demonstrate that the recovery of anthocyanins extracted by MAE was about $45 \%$ of the total obtained with the exhaustive extraction of GJP as well as recoveries of about 21, 24 and $36 \%$ for TPC, ABTS and DPPH, respectively. Comparing the times of $1 \mathrm{~h} 40 \mathrm{~min}$ used for exhaustive extraction of GJP, with a 10 times shorter duration for MAE (10 min), and the non-use of organic solvent, the latter proves to be more advantageous; however, it presented significantly low yields, reaching almost $50 \%$ of the amount of anthocyanins and about one-fifth of TPC. For this reason, more studies evaluating power and time are necessary in order to improve yields. When compared to AEX, the time spent was $24 \mathrm{~h}$ with recoveries of anthocyanins, TPC, ABTS and DPPH of approximately 40, 10, 14 and $17 \%$, respectively.

The rapid action of the microwaves in promoting the penetration of the solvent in the food matrix by molecular movement of the dipole rotation and ionic conduction suits MAE for the extraction of polar active compounds, such as phenolic compounds, including anthocyanins [44,45]. On the other hand, conventional solidliquid extraction processes in food matrices usually apply large amounts of organic solvents for the depletion of the raw material for long periods, thus obtaining higher yields of bioactive compounds. 


\section{Conclusion}

Grape pomace is a source of phenolic compounds which can be extracted by MAE and UAE. However, the results showed that when acidified water solution is used as a solvent, the phenolic contents and antioxidant activity were lower when compared with exhaustive extraction using methanol acidified solution. For ultrasound and microwave extractions, the best condition corresponded to the treatment of MAE with 1,000 W of power and $10 \mathrm{~min}$ time of exposure, where $45 \%$ of the anthocyanins were recovered compared to the exhaustive extraction with methanol acidified solution. For this reason, in order to increase the extraction yields of phenolic compounds and continuously use green chemistry in this process, further research would be recommendable to better understand the application of ethanol aqueous solution as a solvent in MAE and UAE.

\section{Funding}

This article was supported by the Fundação de Amparo à Pesquisa do Estado do Rio Grande do Sul (Funder Id: http:/ / dx.doi.org/10.13039/501100004263, Grant Number: Caciano Zapata Noreña), Conselho Nacional de Desenvolvimento Científico e Tecnológico (Funder Id: http:/ / dx.doi.org/10.13039/501100003593, Grant Number: Caciano Zapata Noreña) and Coordenação de Aperfeiçoamento de Pessoal de Nível Superior (Funder Id: http:/ / dx.doi.org/10.13039/501100002322, Grant Number: Cassiano Brown da Rocha).

\section{Acknowledgment}

The authors thank FAPERGS, CAPES and CNPq for the financial support and Fante Beverage Industry, but especially Eng. Luciane Fante Barreto for the donations.

\section{References}

[1] Yamashita F, Tonraz AC, Fernandes ]C, Moriya S, Benassi MT. Influência de diferentes embalagens de atmosfera modificada sobre a aceitação de uvas finas de mesa var. Itália mantidas sob refrigeração. Ciênc Tecnol Aliment. 2000;20:110-14.

[2] Instituto Brasileiro do Vinho (IBRAVIN). Safra da uva 2015. 2016. <http://www.ibravin.org.br>.

[3] Teixeira A, Baenas N, Domingues-Perles R, Barros A, Rosa E, Moreno DA, et al. Natural bioactive compounds from winery by-products as health promoters: a review. Int ] Mol Sci. 2014;15:15638-78.

[4] De Souza VB, Thomazini M, Baliero JCC, Fávaro-Trindade CS. Effect of spray drying on the physicochemical properties and color stability of the powdered pigment obtained from vinification byproducts of the Bordo grape (Vitis labrusca). Food Bioprod Process. 2015;93:39-50

[5] Muhlack RA, Potumarthi R, Jeffery DW. Sustainable wineries through waste valorization: a review of grape marc utilization for valueadded products. Waste Manage. 2018;72:99-118.

[6] Makris DP, Boskou G, Andrikopoulos NK. Polyphenolic content and in vitro antioxidant characteristics of wine industry and other agrifood solid waste extracts. J Food Compos Anal. 2007;20:125-32.

[7] Aliakbarian B, Fathi A, Perego P, Dehghani F. Extraction of antioxidants from winery wastes using subcritical water. ] Supercrit Fluids. 2012;65:18-24.

[8] Beres C, Costa CNS, Cabezudo I, Da Silva-James NK, Teles ASC, Cruz APG, et al. Towards integral utilization of grape pomace from winemaking process: a review. Waste Manage. 2017;68:581-94.

[9] Poser GLV, Mentz LA. Diversidade biológica e sistemas de classificação. In: Oliveira SCM, Schenkel EP, Cosmann G, Mello ]CP, Mentz LA, Petrovick PR, Org. Farmacognosia da planta ao medicamento, vol. 4, 5th ed. Porto Alegre / FlorianÓpolis: Editora da UFRCS/Editora da UFSC, 2004:75-89.

[10] Giusti MM, Wrolstad RE. Acylated anthocyanins from edible sources and their applications in food systems. Biochem Eng ]. 2003;14:21725.

[11] Barba F], Zhu Z, Kouba M, Sant'ana AS, Orlien V. Green alternative methods for the extraction of antioxidant bioactive compounds from winery wastes and by-products: a review. Trends Food Sci Technol. 2016;49:96-109.

[12] He B, Zhang L, Yue X, Liang ], Jiang ], Gao X, et al. Optimization of ultrasound-assisted extraction of phenolic compounds and anthocyanins from blueberry (Vaccinium ashei) wine pomace. Food Chem. 2016;204:70-6.

[13] Cai Z, Qu Z, Lan Y, Zhao S, Ma X, Wan Q, et al. Conventional, ultrasound-assisted, and accelerated-solvent extractions of anthocyanins from purple sweet potatoes. Food Chem. 2016;197:266-72.

[14] Ongkowwijoyo P, Luna-Vital DA, De Mejia EC. Extraction techniques and analysis of anthocyanins from food sources by mass spectrometry: an update. Food Chem. 2018;250:113-26.

[15] Sharmila G, Nikitha VS, Ilaiyarasi S, Dhivya K, Rajasekar V, Manoj KN, et al. Ultrasound assisted extraction of total phenolics from Cassia auriculata leaves and evaluation of its antioxidant activities. Ind Crops Prod. 2016;84:13-21. 
[16] Zeković Z, Pintać D, Majkić T, Vidović S, Mimica-Dukić N, Teslić N, et al. Utilization of sage by-products as raw material for antioxidants recovery-Ultrasound versus microwave-assisted extraction. Ind Crops Prod. 2017;99:49-59.

[17] Khan MK, Ahmad K, Hassan S, Imran M, Ahmad N, Xu C. Effect of novel technologies on polyphenols during food processing. Innov Food Sci Emerg Technol. 2018;45:361-81.

[18] Chemat F, Rombaut N, Sicaire A, Meullemiestre A, Fabiano-Tixier A, Abert-Vian M. Ultrasound assisted extraction of food and natural products. Mechanisms, techniques, combinations, Protocols and applications. Ultrason Sonochem. 2017;34:540-60.

[19] Pingret D, Fabiano-Tixier A, Chemat F. Degradation during application of ultrasound in food processing: a review. Food Control. 2013;31:593-606.

[20] Liazid A, Guerrero RF, Cantos E, Palma M, Barroso CG. Microwave assisted extraction of anthocyanins from grape skins. Food Chem. 2011;124:1238-43.

[21] Álvarez A, Poejo ], Matias AA, Duarte CMM, Cocero M], Mato RB. Microwave pretreatment to improve extraction efficiency and polyphenol extract richness from grape pomace. Effect on antioxidant bioactivity. Food Bioprod Process. 2017;106:162-70.

[22] Farzaneh V, Carvalho IS. Modelling of microwave assisted extraction (MAE) of anthocyanins (TMA). ] Appl Res Med Aromat Plants. 2017;6:92-100.

[23] Fonteles TV, Leite AKF, Da Silva ARA, Fernandes FAN, Rodrigues S. Sonication effect on bioactive compounds of cashew apple bagasse. Food Bioproc Tech. 2017;10:1854-64.

[24] Association of Official Analytical Chemists (AOAC). Official methods of analysis of AOAC International, 19th ed. Gaithersburg, MD: AOAC, 2012:2v.

[25] Kuck LS, Wesolowski JL, Noreña CPZ. Effect of temperature and relative humidity on stability following simulated gastro-intestinal digestion of microcapsules of Bordo grape skin phenolic extract produced with different carrier agents. Food Chem. 2017;230:257-64.

[26] Sánchez-Alonso I, Jiménez-Escrig A, Saura-Calixto F, Borderías A]. Antioxidant protection of white grape pomace on restructured fish products during frozen storage. LWT Food Sci Technol. 2008;41:42-50.

[27] Rodrigues E, Mariutti LRB, Mercadante AZ. Carotenoids and phenolic compounds from Solanum sessiflorum, na unexploited amazonian fruit, and their scavenging capacities against reactive oxygen and nitrogen species. J Agric Food Chem. 2013;61:3022-9.

[28] Singleton VL, Rossi ]A. Colorimetry of total phenolics with phosphomolybdic-phosphotungstic acid reagents. Am ] Enol Viticult. $1965 ; 16: 144-5$

[29] Lee ], Durst RW, Wrolstad RE. Determination of total monomeric anthocyanin pigment content of fruit juices, beverages, natural colorants, and wines by the $\mathrm{pH}$ differential method: collaborative study. ] AOAC Int. 2005;88:1269-78.

[30] Re R, Pellegrini N, Proteggente A, Pannala A, Yang M, Rice-Evans C. Antioxidant activity applying na improved ABTS radical cátion decolorization assay. Free Radical Biol Med. 1999;26:1231-7.

[31] Brand-Williams W, Cuvelier ME, Berset C. Use of a free radical method to evaluate antioxidant activity. LWT Food Sci Technol. 1995;28:2530.

[32] Palou E, López-Malo A, Barbosa-Cánovas GV, Welti-Chanes ], Swanson BG. Polyphenoloxidase activity and color of blanched and high hydrostatic pressure treated banana puree. J Food Sci. 1999;64:42-5.

[33] Cordillo B, Rodríguez-Pulido F], Conzález-Miret ML, Quijada-Morín N, Rivas-Conzalo ]C, García-Estévez I, et al. Applications of differential colorimetry to evaluate anthocyanin-flavonol-flavanol ternary copigmentation interactions in model solutions. J Agr Food Sci. 2015;63:7645-53.

[34] Yu ]. Thermal stability of major classes of polyphenols in skins, seeds and stems of grape pomace. In: Câmara ]S, editor. Grapes vol. 11. Nova Science Publishers, Inc, 2014:273-85.

[35] Muñoz O, Sepúlveda M, Schwartz M. Effects of enzymatic treatment on anthocyanic pigments from grapes skin from chilean wine. Food Chem. 2004;87:487-90.

[36] Coula AM, Thymiatis K, Kaderides K. Valorization of grape pomace: drying behavior and ultrasound extraction of phenolics. Food Bioprod Process. 2016;100:132-44.

[37] Hayat K, Zhang X, Farooq U, Abbas S, Xia S, Jia C, et al. Effect of microwave treatment on phenolic content and antioxidant activity of citrus mandarin pomace. Food Chem. 2010;123:423-9.

[38] Dias DRC, Barros ZMP, De Carvalho CBO, Honorato FA, Guerra NB, Azoubel PM. Effect of sonification on soursop juice quality. LWT Food Sci Technol. 2015;62:883-9.

[39] Benmeziane F, Abdourhamane AM, Guedaoura A. Nutritional quality and bioactive compounds of some fruit juices. Adv Environ Biol. 2016;10:242-50.

[40] Kaur C, Kapoor H. Antioxidants in fruits and vegetables - the millennium's health. Int ] Food Sci Technol. 2001;36:703-25.

[41] Baljeet S, Roshanlal Y, Ritika B. Effect os cooking methods and extraction solvents on the antioxidant activity of summer squash (Cucurbita pepo) vegetable extracts. Int Food Res ]. 2016;23:1531-40.

[42] Lovrić V, Putnik P, Kovačević DB, Jukić M, Verica Dragović-Uzelac V. Effect of microwave-assisted extraction on the phenolic compounds and antioxidant capacity of blackthorn flowers. Food Technol Biotechnol. 2017;55:243-50.

[43] Gordillo B, Sigurdson CT, Lao F, González-Miret ML, Heredia F], Giusti MM. Assessment of the color modulation and stability of naturally copigmented anthocyanin-grape colorants with different levels of purification. Food Res Int. 2018;106:791-9.

[44] Caldas TW, Mazza KEL, Teles ASC, Mattos GN, Brígida AIS, Conte-Júnior CA, et al. Phenolic compounds recovery from grape skin using conventional and non-conventional extraction methods. Ind Crops Prod. 2018;111:86-91.

[45] Dranca F, Oroian M. Optimization of ultrasound-assisted extraction of total monomeric anthocyanin (TMA) and total phenolic content (TPC) from eggplant (Solanum melongena L.). Peel. Ultrason Sonochem. 2016;31:637-46. 